ECONOMICS OF FLEX-CROPPING IN SOUTHWESTERN SASRATCHEWAN

\author{
R.P. Zentner, K.R. Handford, E.B. Dyck, \\ C.A. Campbell, and F. Selles \\ Research Station \\ Research Branch, Agriculture Canada \\ Swift Current, Saskatchewan \\ S9H $3 \times 2$
}

\begin{abstract}
The economic returns and riskiness of spring wheat production using fixed sequence rotations were compared to flexible cropping systems wherein the annual crop/fallow decisions are based on the level of available water at or near the time of planting. The study used 25 years of data from a crop rotation experiment at Swift Current, Saskatchewan. Fixed cropping systems included fallow-wheat $(F-W)$, fallow-wheat-wheat $(F-W-W)$, and continuous wheat (CW), while flex-cropping systems included 2YR-IF, 3YR-IF, and CW-IF. The 2YR-IF system permitted the entire farm to be cropped when available spring water in stubble was favorable, but if water was unfavorable, $50 \%$ of the area was fallowed. The 3YR-IF system permitted two-thirds of the land area to be cropped whenever spring water was favorable, but only one-third of the area was cropped if water was unfavorable. Under CW-IF, the entire farm was cropped in years with favorable spring water; it was fallowed in years when water was not favorable. Each flexcropping system was constructed using two decision criteria: (i) available soil water in stubble measured about 1 May (SSW), and (ii) SSW plus precipitation received from date of spring soil sampling up to 31 May (TSW). Five threshold levels of water were defined for each decision criteria, with ssw ranging between 35 and $95 \mathrm{~mm}$ and TSW ranging between 65 and $125 \mathrm{~mm}$. The systems were evaluated at wheat prices of $\$ 110, \$ 147$, and $\$ 184 t^{-1}$, calculated with and without all-risk crop insurance. Expected net returns were generally higher for the flexible systems at all wheat prices. Income variability for flex-cropping systems was usually much lower than for $C W$, and it was often as low as that of the traditional $\mathrm{F}-\mathrm{W}$ system which is known for its low income variability. This was particularly true when flex-cropping was combined with all-risk crop insurance. The TSW decision criterion was usually superior to SSW, because it was more highly correlated with final grain yields than was SSW. In all cases the optimum flex-cropping systems used fallow less frequently than is the tradition in this region. The study concluded that wide-spread use of flex-cropping practices by producers in southwestern Saskatchewan could increase farm-level net returns and reduce the risks of financial loss, while potentially reducing soil degradation.
\end{abstract}

\title{
INTRODUCTION
}

The Brown soil zone is characterized by low and variable precipitation and by high evaporation demands, which together place cereal crops under severe water stress during much of the growing season. In response to this, producers have traditionally employed a 2-yr fixed rotation of fallow and spring wheat. Fallowing is practised primarily to increase soil water reserves, thereby reducing dependence of the crop on uncertain growing season precipitation. The benefits from using this production system are reflected mainly in higher, more stable grain yields and economic returns (Zentner and Campbell 1988). However, frequent fallowing, when combined with extensive use of mechanical tillage for weed control, is a major cause of excessive soil erosion, declining soil organic matter quantity and quality, and soil salinization (Campbell et al. 1986). 
Recent studies have suggested that flexible cropping systems, which use spring soil water reserves as the main criterion for deciding whether to plant stubble land, offer producers opportunity for higher net returns and lower income variability than many fixed rotations, plus the potential for improved soil conservation (Weisensel et al. 1991). Flex-cropping is based on the notion of a high correlation between crop yields and the level of soil water reserves at planting time (Staple and Lehane 1954). This technique is intended to reduce the downside risk associated with stubble cropping by opting to fallow in years when spring soil water reserve in stubble land is below some threshold value, and to crop stubble land when spring soil water reserve is favorable.

The objective of this study was to compare net returns and riskiness of fixed versus flexible cropping systems for spring wheat production in southwestern saskatchewan, based on results from a $25-y$ y crop rotation experiment.

\section{MATERIAS AND METHODS}

Cropping systems, Management, and Sampling

The experiment was initiated in 1967 at the Agriculture Canada Research station near swift Current, Saskatchewan on a Swinton silt loam. Twelve crop rotations were initially established in the experiment, but only 3 are used in this study, namely, fallow-wheat (E-W), fallow-wheat-wheat (E-W-W), and continuous wheat (CW).

The methods used in management of the plots reflect the generally recommended practices for this region. Farm-size equipment was used to perform all cultural and tillage operations. Areas being cropped received one tillage operation to prepare the seedbed. Fertilizer $\mathrm{N}$ and $\mathrm{P}$ were applied in accordance with soil test guidelines provided by the Saskatchewan Advisory Council on soils. The 25-yr mean rate of $\mathrm{N}$ fertilizer applied to wheat grown on fallow was $7.2 \mathrm{~kg}$ $\mathrm{ha}^{-1}$; for wheat grown on stubble, the mean $\mathrm{N}$ rates were $27.7 \mathrm{~kg} \mathrm{ha}^{-1}$ for $\mathrm{F}-\mathrm{W}-\mathrm{W}$ and $30.5 \mathrm{~kg} \mathrm{ha}{ }^{-1}$ for $\mathrm{CW}$. Nitrogen was broadcast as ammonium nitrate $(34-0-0)$ and soil incorporated by tillage used to prepare the seedbed. Phosphorus was applied with the seed as monoammonium phosphate (11-48-0 or 11-51-0) at an average rate of $9.7 \mathrm{~kg} \mathrm{P} \mathrm{ha}{ }^{-1}$.

Weeds were controlled in the wheat crops using recommended application rates and types of herbicides for the region. On fallow areas weeds were controlled by an average of 3.8 (range 2 to 5 ) tillage operations during the summer period, plus a late fall application of $2,4-D$ ester for control of winter annuals.

Grain yields were determined by combining a $5 \mathrm{~m}$ wide strip lengthwise through the center of each plot. Areas that had been cropped were left untilled after harvest, but each received $2,4-D$ ester herbicide for control of winter annual weeds.

Soll cores were taken from each plot by segment to the $120 \mathrm{~cm}$ depth in late April or early May, prior to seeding, and at harvest (Table 1). The samples were analyzed for moisture (gravimetric), $\mathrm{NO}_{3}-\mathrm{N}$, and bicarbonate-extractable $\mathrm{P}$. Available spring soil water was calculated by subtracting the lowest volume of available soil water (lower limit) observed at harvest in this study (i.e, 148 $\mathrm{mm}$ in the 0-to 120-cm soil depth) from the volumetric water content measured in spring. Weather variables, including growing season precipitation (Table 1), were measured at a nearby meteorological station. 
Table 1. Precipitation received during the growing season, and dates of spring soil sampling, planting, and grain harvest.

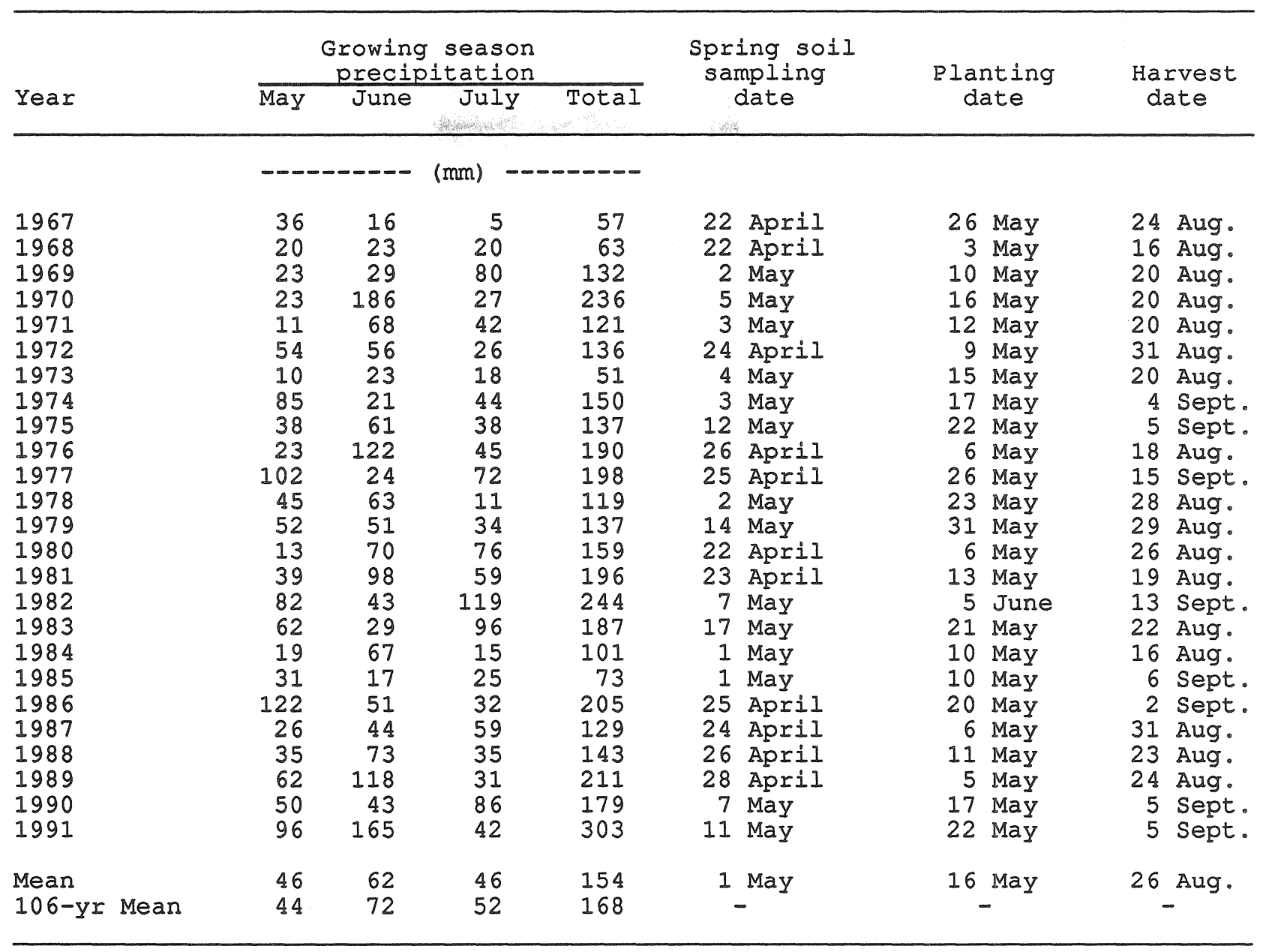

\section{Flex-Crop Considerations}

Analysis was based on inputs (e.g., nutrients applied, herbicides, machine operations, etc.) and outputs (grain yields) for the 1967 to 1991 period for the three fixed systems. In addition, three sets of flex-cropping systems were constructed (Fig. 1). The CW-IF system (Fig. 1a) permits the entire land base of a farm to be cropped (or fallowed) in any year, except that land cannot be fallowed in consecutive years. The $2 Y R-I F$ and $3 Y R-I F$ systems (Fig. $1 b$ and $1 c$ ) are modifications of $\mathrm{CW}-\mathrm{IF}$. They reflect arbitrary constraints placed on the amount of land that may be fallowed in any particular year because of practical limitations of this production system (Weisensel et al. 1991).

The 2YR-IF system (Fig. 1b) permits the entire land base to be cropped in years when available water reserves in stubble are favorable (i.e., greater than some threshold value), but constrains the area fallowed to $50 \%$ of the total land area in years when available water reserve in stubble is unfavorable. The 3YR-IF system (Fig. 1C) maintains at least one-third of the land base in fallow each year. In years when available water reserves in stubble are favorable, twothirds of the land area is cropped (i.e., the one-third portion that was fallowed and the one-third portion on which wheat was planted on fallow the previous year). Alternately, when available water reserve is unfavorable for stubble cropping, the area fallowed can increase to two-thirds of the land base; only the one-third area of land that was fallowed the previous year is cropped. As with the CW-IF system, land cannot be fallowed in consecutive years. 
a) CW-IF Rotation

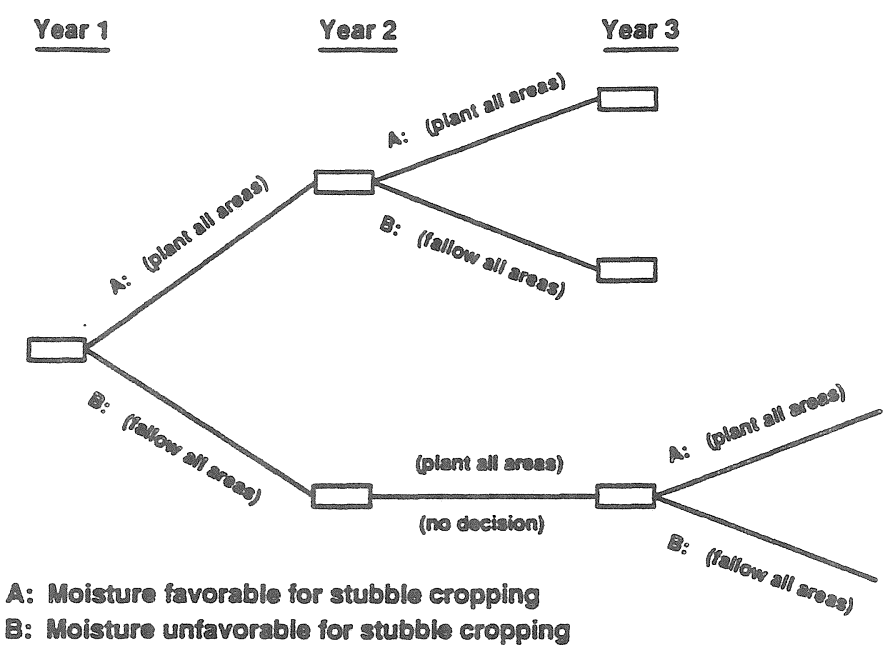

b) 2YR-IF Rotation

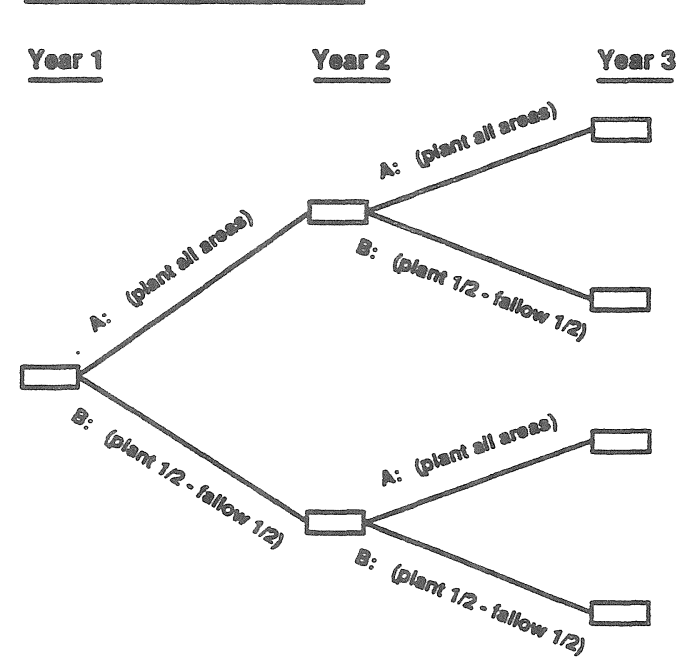

c) 3YR - IF Rotation

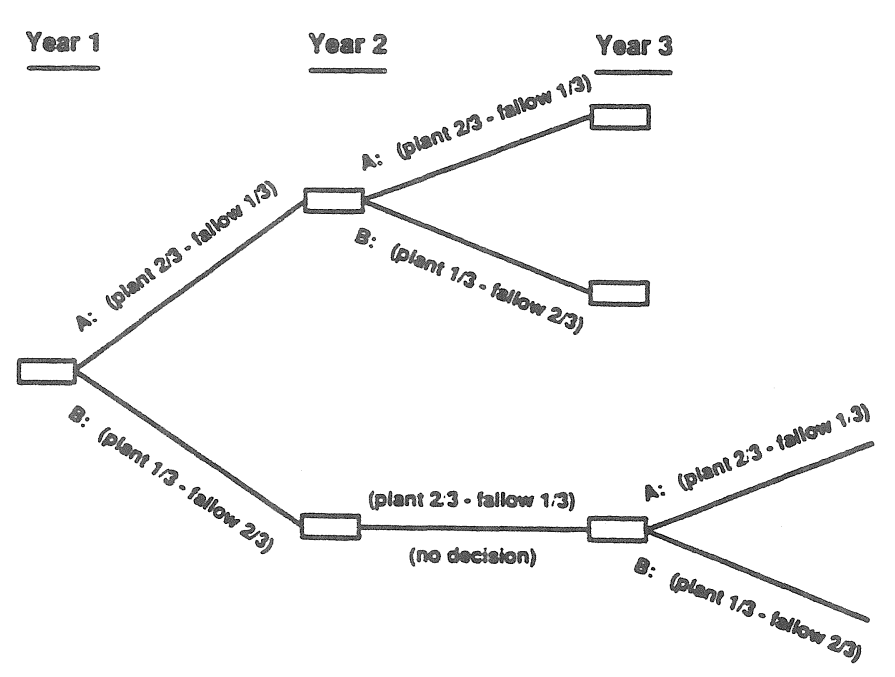

Figure 1. Schematic of the CW-IF, 2YR-IF, and $3 Y R-I F$ flem-crop systems. 
Each flex-cropping system was constructed using two decision making criteria. These were: (i) available water in the 0- to 120-cm soil depth measured in early spring (SSW), and (ii) total available spring water (TSW) (i.e., SSW plus precipitation received from date of soil sampling up to 31 May). The first criterion reflects the situation in which the crop/fallow decision is made in early spring, based solely on the amount of available soil water reserve measured about $1 \mathrm{May}$ (present recommended flex-cropping practice). The second criterion reflects the notion of delaying the crop/fallow decision until later in May, or until sufficient May precipitation is received so that TSW exceeds some threshold level. If the threshold TSW level is not reached by $31 \mathrm{May}$, all or part of the stubble land is fallowed, subject to the earlier designated area constraints. Five threshold levels of available water were arbitrarily assumed for each decision criterion. For the SSW criterion these were 35, 50, 65, 80, and $95 \mathrm{~mm}$, and for TSW they were $65,80,95,110$, and $125 \mathrm{~mm}$.

The flex-cropping systems were constructed using annual data taken from the F-W-W rotation. Grain yields for the flex-cropping systems under the TSW decision criterion were not adjusted for date of planting. While delayed planting is often reported to decrease cereal grain yields and quality in northerly regions of the Canadian Prairies, in southwestern saskatchewan, the planting of CWRS wheat can often be delayed until May in most years with little negative impact on these characteristics.

\section{Economic Considerations}

Production costs, net returns, and net present value (NPV) were calculated for each rotation using a budgeting framework. Net return was defined as the income remaining after paying for all cash costs (e.g., seed, fertilizer, herbicides, fuel, oil, machine repair, labor, crop insurance, land tax, miscellaneous, and interest on operating capital), plus overhead costs associated with machines and grain storage. The NPV were calculated using a 5\% discount rate. The discount rate captures the time-value of money by placing a lower weight on future net returns compared to those earned in the present or starting year (Doll and Orazem 1978). No allowance was made for differences among cropping systems with regard to management requirements, income tax considerations, or costs associated with land equity. Annual costs of inputs and field operations (Table 2) were held at 1991 values (Saskatchewan Agriculture and Food 1991). Each rotation was evaluated at three wheat price levels (Table 2), and with and without participation in the Canada/saskatchewan Crop Insurance Program. All-risk crop insurance is an alternate method of risk reduction available to area producers which could be a substitute for, or a complement to, any risk benefits of flex-cropping systems. Participation in the Program was assumed to be at the $70 \%$ yield coverage and variable price options. Premium rates and payout criteria for individual coverage within Risk Area 10 of Saskatchewan were assumed; both premium and payout levels varied directly with wheat price.

Grain yields, available spring soil water in the 0- to 120-cm soil depth, annual net returns, and NPVs were compared among rotations using analysis of variance for split-plot design, with years as main plot and rotations as subplot (Statistical Analysis system Institute Inc. 1985). Differences among treatment means were determined by least-significant-difference (LSD) at $P=0.05$. Correlation analysis was used to examine the relationships between wheat yields and various spring available water variables (Little and Hills 1978). Riskiness of the rotations was assessed using stochastic dominance analysis as described by Anderson et al. (1977). The sets of risk efficient rotations, based on the distributions of annual net return, were established for risk-neutral producers, and for groups of low-, medium-, and high-risk averse producers, as defined by Zentner et al. (1992). Risk-neutral producers are those seeking to maximize expected profit (or net return); they are not concerned with variability of profit or the nature of the distribution of possible outcomes. Alternately, risk averse producers are willing to give up some amount of expected net return (the risk premium) in order to reduce, or avoid the occurence of low or negative outcomes. The size of the risk premium is directly proportional to the degree of risk aversion held by the producers. 
Table 2. Summary of economic parameters.

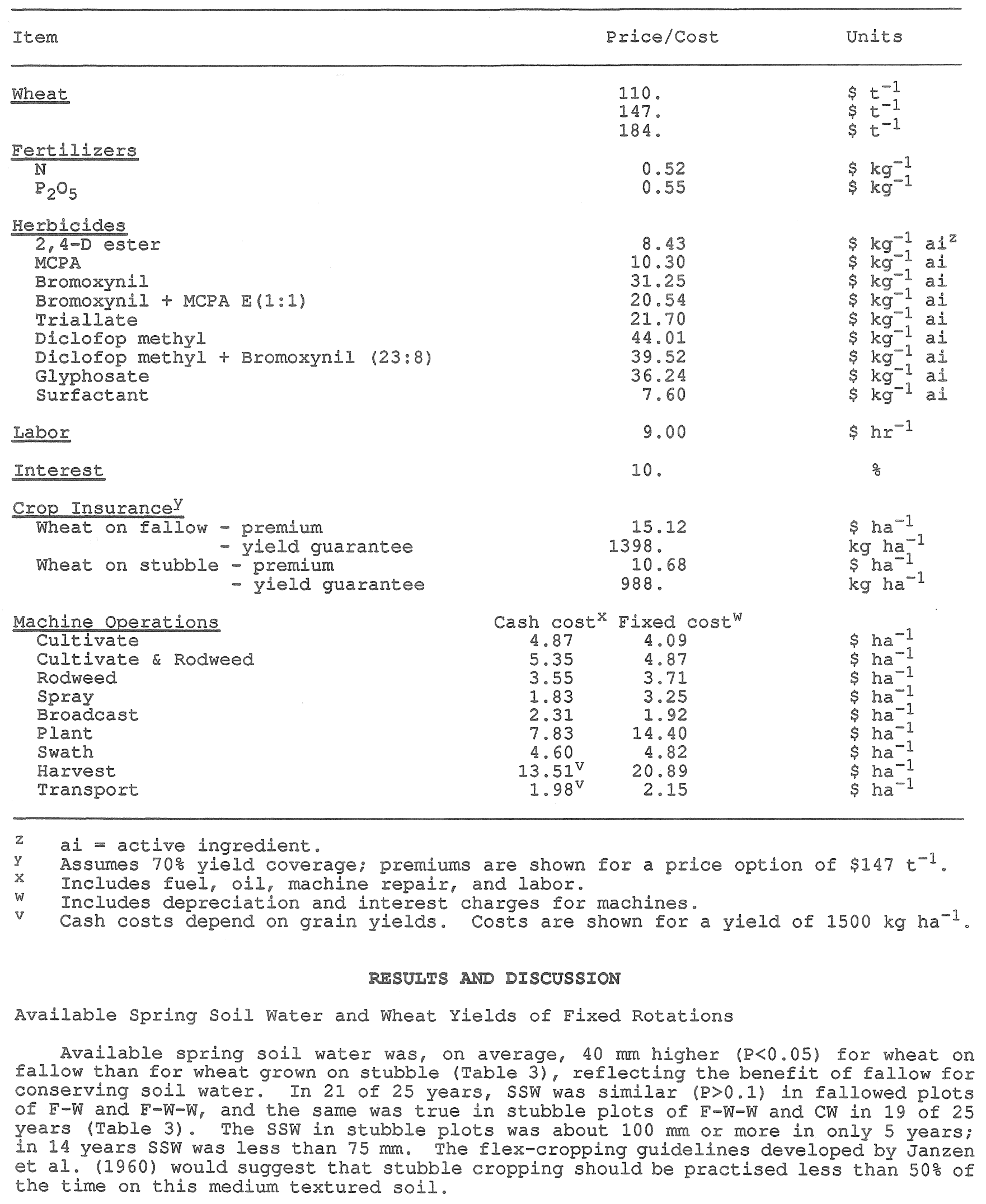


Table 3. Available spring soil water (SSW) and wheat yields by rotation-phase.

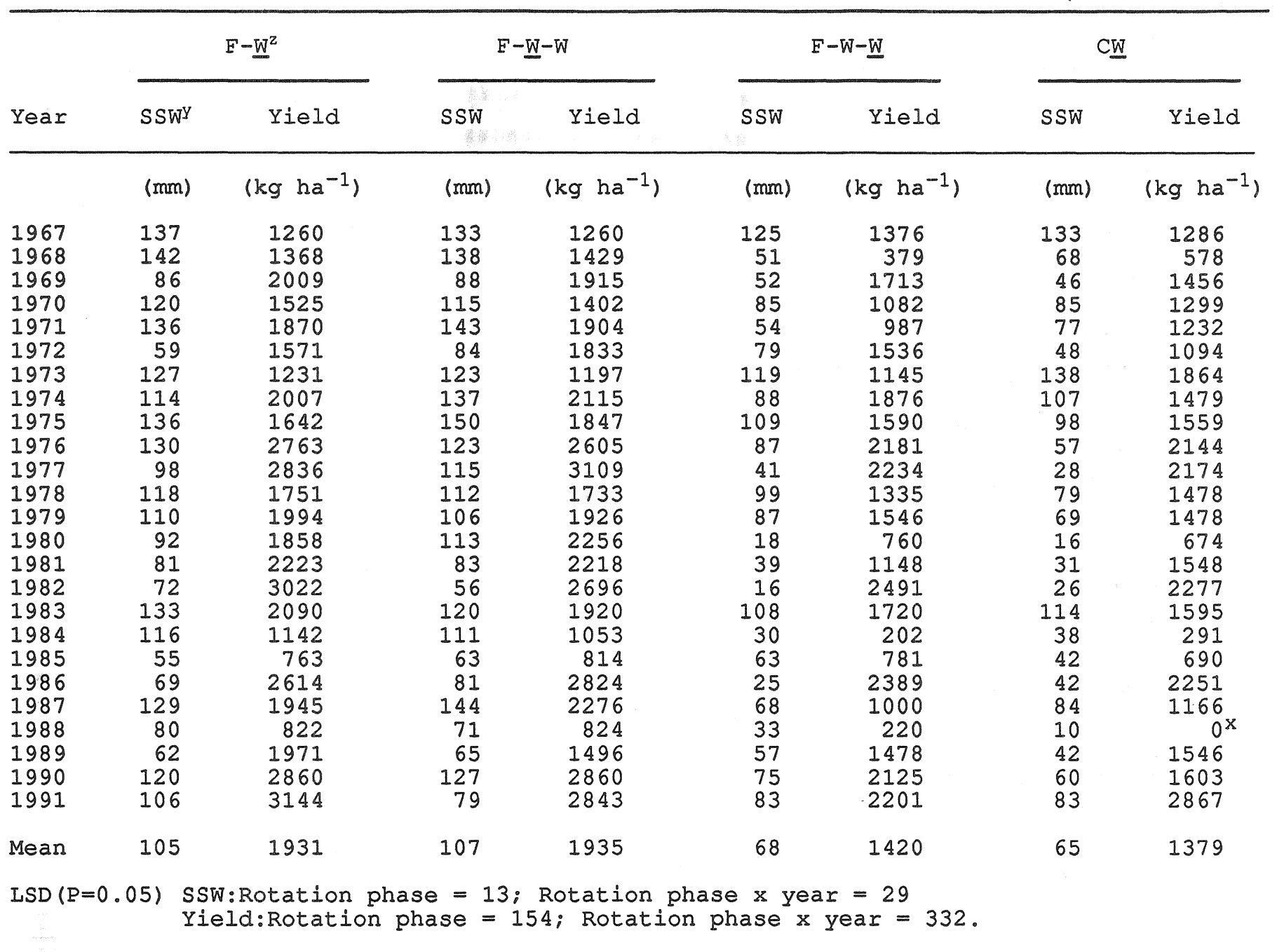

$z$ Values were averaged over 3 replicates, and are shown for the rotation-phase underlined.

$y$ Available spring soil water in 0 - to $120-\mathrm{cm}$ soil depth.

$x$ Complete crop failure caused by drought.

Wheat yields averaged $1933 \mathrm{~kg} \mathrm{ha}^{-1}$ when grown on fallow and $1400 \mathrm{~kg} \mathrm{ha}^{-1}$ when grown on stubble (Table 3). Yields were also more variable on stubble (CV=49\%) than on fallow ( $\mathrm{CV}=36 \%$ ). In 9 of 25 of years, yields of stubble-seeded wheat averaged more than $85 \%$ of fallow-seeded wheat, but in 5 years stubble-wheat yields averaged less than $50 \%$ of fallow-wheat yields.

Yields of stubble-wheat were significantly correlated with SSW, but this was not so for fallow-wheat (Table 4). Stored soil water in fallow is usually sufficient to ensure good germination and plant establishment. The simple correlations between grain yield and supplies of spring water increased as more of the precipitation received in May was added to SSW (Table 4). Thus, basing the crop/fallow decision for flex-cropping options on SSW alone may not provide as good a prediction of final grain yield as using SSW plus some or all of May's precipitation. 
Table 4. Simple correlation coefficients between wheat yields and various water parameters.

\begin{tabular}{lcc}
\hline Parameter & $\begin{array}{c}\text { Yield of wheat } \\
\text { on fallow }\end{array}$ & $\begin{array}{c}\text { Yield of wheat } \\
\text { on stubble }\end{array}$ \\
\hline SSW $^{2}$ & NSY $^{Y}$ & 0.17 \\
TSW to 14 May & NS & 0.28 \\
TSW to 21 May & 0.21 & 0.40 \\
TSW to 31 May & 0.35 & 0.51 \\
TSW to 31 July & 0.71 & 0.72 \\
\hline
\end{tabular}

2 Available spring soil water in 0 - to $120-\mathrm{cm}$ soil depth.

$y$ Values designated NS were not significant: all others were significant at $P<0.05$.

× TSW = SSW plus precipitation received to specified dates.

As expected, the highest correlations with wheat yields were obtained when SSW was added to precipitation received over the entire growing season ( 1 May to 31 July) (Table 4). However, during the 25 -yr study period, the correlation between SSW and GSP was negative $(P<0.05)(\underline{r}=-0.31$ for fallow plots, and $r=-0.26$ for stubble plots), which could be detrimental to the overall effectiveness of adopting the flex-cropping approach. For example, in 1977, 1982, and $1986 \mathrm{SSW}$ in stubble plots was very low, but the resulting grain yields were very high due to above-normal GSP. If flex-cropping was being used in these situations based only on SSW, these high yielding stubble years would be missed. In 1967, 1973, and 1978, SSW was very favorable for stubble cropping, but final yields were low because of below-normal or poorly distributed GSP. Here flexcropping, which would have recommended stubble cropping, would have resulted in grain yields that were too low to recover all input costs, particularly when expected wheat price is low. These results imply that flex-cropping decision criteria cannot be expected to be perfect predictors. Nevertheless, these systems may have superior economic performance to the fixed rotations wherein spring water levels are not considered in the crop/fallow decision.

Production Costs for Fixed Rotations

Annual cash costs for the $\mathrm{F}-W$ system averaged $\$ 81 \mathrm{ha}^{-1}$ (range $\$ 62$ to $\$ 106$ $\left.\mathrm{ha}^{-1}\right)$, for $\mathrm{F}-\mathrm{W}-\mathrm{W} \$ 97 \mathrm{ha}^{-1}$ (range $\$ 69$ to $\$ 129 \mathrm{ha}^{-1}$ ), and for $\mathrm{CW} \$ 140 \mathrm{ha}^{-1}$ (range $\$ 97$ to $\$ 186 \mathrm{ha}^{-1}$ ). Overhead costs associated with ownership of equipment and grain storage buildings averaged $\$ 42, \$ 48$, and $\$ 62 \mathrm{ha}^{-1}$ for $F-W, F-W-W$, and $C W$, respectively. Thus, overall production costs per unit of land area for the complete rotation systems averaged $18 \%$ higher for $F-W-W$ and $64 \%$ higher for $C W$ than for $F-W$.

The cash costs associated with fallowing a unit of land in the $F-W-W$ rotation averaged $\$ 36 \mathrm{ha}^{-1}$ (Table 5), with costs for machine operations (fuel, oil, and repairs) and labor being the major expenditures. Cash costs to produce wheat in this same rotation averaged $\$ 128 \mathrm{ha}^{-1}$, with the costs being slightly higher when wheat was grown on stubble compared to fallow, primarily because of higher fertilizer requirements for stubble-seeded crops. Cost of the premium for the Canada/Saskatchewan Crop Insurance Program (for any wheat price) was lower for wheat grown on stubble compared to fallow, but so too was the guaranteed level of yield coverage (Table 2). The unit area cost of stubble-cropping averaged about $\$ 10 \mathrm{ha}^{-1}$ higher for $\mathrm{CW}$ than for $\mathrm{F}-\mathrm{W}-\mathrm{W}_{\text {, primarily due to the }}$ slightly higher rates of $\mathrm{N}$ fertilizer and the application of additional herbicides to control quackgrass in $\mathrm{CW}$ in several years. 
Table 5. Costs of fallowing and producing wheat by rotation-phase for $F-W-W$.

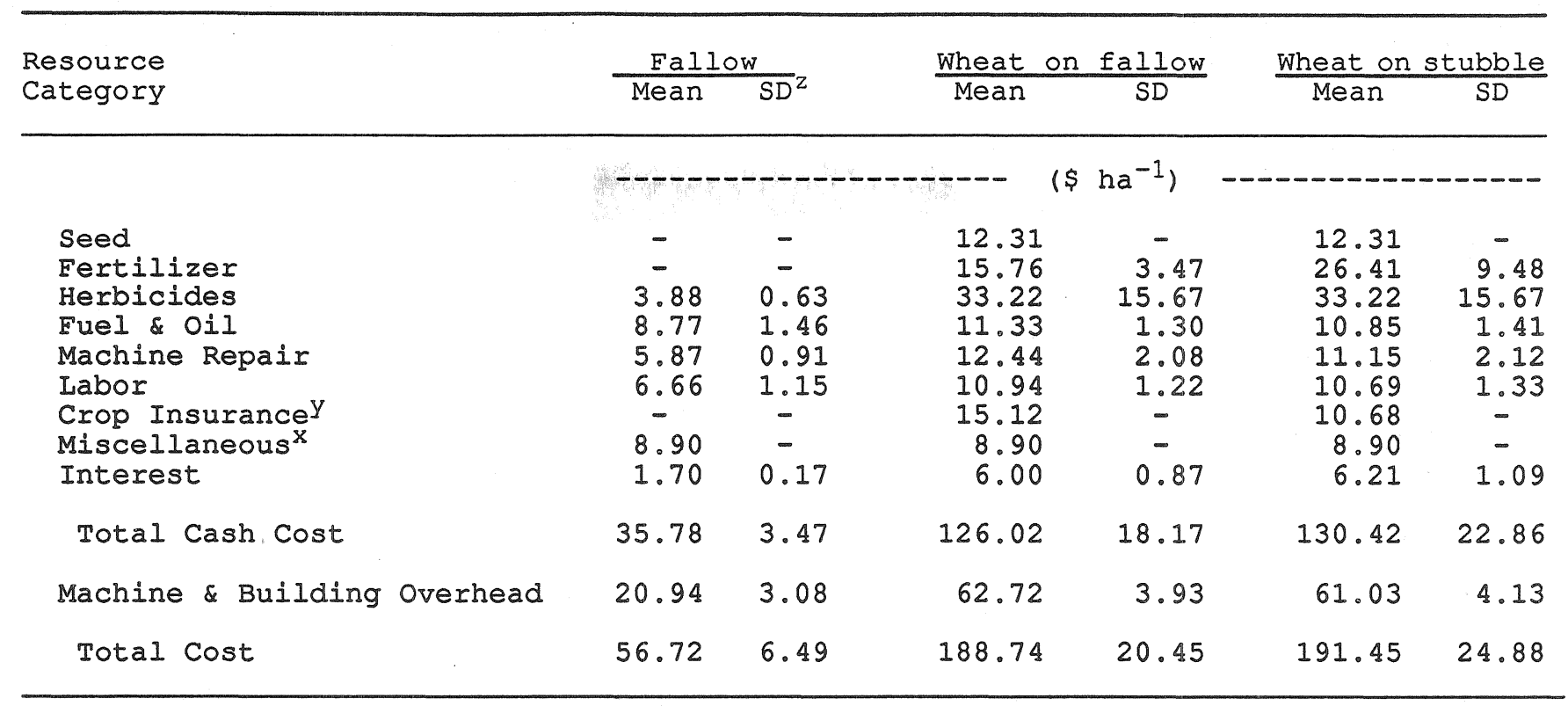

$z$ Standard deviation calculated over years.

$y$ Shown for a wheat price option of $\$ 147 t^{-1}$

\& Includes land taxes and an allowance for electricity and other utility costs.

\section{Elex-Cropping Systems}

The annual sequence of fallow and cropping activities for the simulated flex-cropping systems reflect the vagaries of the weather that prevailed over the 25-year study period (Table 6). During the first 10 to 13 years, available spring water conditions were consistently favorable for stubble cropping for both decision criteria, particularly at lower threshold water levels (Table 3 ). In contrast, since 1980, available spring soil water conditions have been lower, and thus the frequency of stubble cropping has tended to be more variable.

The average cropping intensities (i.e., the proportion of the total land area cropped each year) for the flex-cropping systems were highest for the $2 Y R-I F$ system, and lowest for 3YR-IF (Table 7). Further, cropping intensities were generally higher when TSW rather than SSW was used as the decision criterion. For both water criteria, cropping intensities declined with increasing threshold water levels. Although the average cropping intensities were sometimes similar for several flex-cropping systems and decision criteria, the annual sequences of fallow and cropping activities differed among all systems (Table 6). By comparison, cropping intensities for the fixed rotations, are 50\%, $67 \%$, and $100 \%$ for $F-W, F-W-W$, and $C W$, respectively.

Net Returns and NPV for Fixed and Flex-Crop Rotations

Average annual net returns and the 25-yr total NPV for the rotations were directly related to the price for wheat (Tables 8 and 9). At a wheat price of $\$ 110 t^{-1}$, the rotations did not generate sufficient income to recover cash plus fixed input costs in most years; however, at higher wheat prices all cropping systems were profitable. The flex-cropping systems usually provided similar or higher net returns than the fixed rotations. Income variability (as measured by standard deviation) was usually lower with flex-cropping systems compared to $\mathrm{CW}$ (with a few exceptions), but this was not so when they were compared to the fixed $\mathrm{F}-\mathrm{W}$ or $\mathrm{F}-\mathrm{W}-\mathrm{W}$ systems. One notable exception was that annual income variability was often greater for $C W-I F$ at the higher threshold water levels than for the fixed CW rotation. This reflects the concern of Weisensel et al. (1991) that under CW-IF and high threshold water levels, the entire farm could cycle between fallow and crop in alternate years (Table 6) and thereby contribute to greater income variability. 
Table 6. Sequences of fallow and cropping activities for the CW-IF system under two decision criteria at three selected threshold water values ${ }^{2}$.

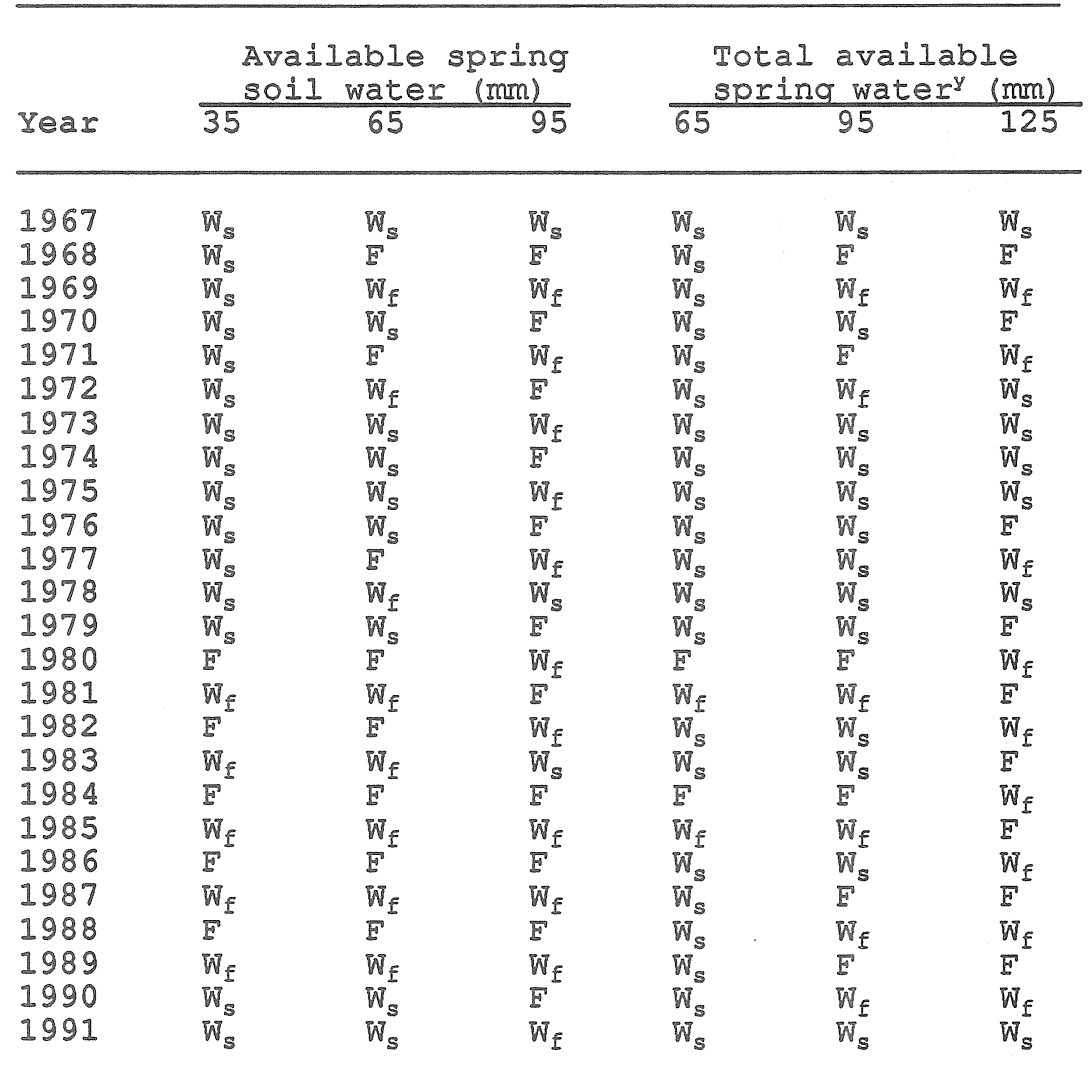

$z \quad F=$ fallow, $W_{f}=$ wheat grown on fallow, $W_{s}$ = wheat grown on stubble.

$y$ Available spring soil water plus precipitation from date of soil sampling up to $31 \mathrm{May}$.

Table 7. Average proportion of land area cropped each year with flexcrop rotations ${ }^{2}$.

\begin{tabular}{|c|c|c|c|c|c|c|c|c|c|c|}
\hline \multirow[b]{2}{*}{ Rotation } & \multicolumn{5}{|c|}{$\begin{array}{l}\text { Available spring } \\
\text { soil water (mm) }\end{array}$} & \multicolumn{5}{|c|}{$\begin{array}{l}\text { Total available } \\
\text { spring water (mm) }\end{array}$} \\
\hline & $\overline{35}$ & 50 & 65 & 80 & 95 & 65 & 80 & 95 & 11 & 125 \\
\hline $2 \mathrm{YR}-I E$ & 90 & 86 & 76 & 72 & 60 & 96 & 84 & 82 & 78 & 70 \\
\hline $3 Y R-I F$ & 60 & 59 & 55 & 55 & 52 & 64 & 60 & 59 & 57 & 55 \\
\hline$C W-I E$ & 80 & 76 & 68 & 64 & 56 & 92 & 80 & 76 & 72 & 64 \\
\hline
\end{tabular}

z Proportion of land area cropped each year for the fixed rotations of $E-W, F-W-W$, and $C W$ are $50 \%, 67 \%$, and $100 \%$, respectively. 
Participation in the Canada/Saskatchewan Crop Insurance Program had relatively little impact on average annual net returns and NPV for most cropping systems except $\mathrm{CW}$, where there was a slight increase (Tables 8 and 9). The small reduction in mean economic returns for most rotations reflects the added annual cost of the insurance premiums compared to the infrequent and often small payouts received from the insurance program. However, crop insurance reduced the annual variability of net returns for all systems. The extent of these reductions increased with cropping intensity, because of the more variable yields of stubble-grown wheat. Within $C W$ and the comparable $C W-I F$ rotations, and within $F-W-W$ and the comparable 3YR-IF rotations, crop insurance was generally more effective in reducing annual income variability than was flex-cropping alone (i.e., without crop insurance). However, the greatest reductions in income variability occurred when all-risk crop insurance and flexcropping were combined.

At a wheat price of $\$ 110 t^{-1}$ there was often little difference in average annual net returns among $F-W, F-W-W$, and the flex-crop rotations (values ranged from a loss of $\$ 10 \mathrm{ha}^{-1}$ to a profit of $\$ 5 \mathrm{ha}^{-1}$ ) (Tables 8 and 9). Annual income variability was lowest for F-W, and the crop insured $3 Y R-I F$ and $F-W-W$ systems (standard deviations of about $\$ 25$ to $\left.\$ 35 \mathrm{ha}^{-1}\right)$ i it was intermediate for uninsured $\mathrm{F}-\mathrm{W}-\mathrm{W}$ and $3 \mathrm{YR}-\mathrm{IF}$ and for insured $2 Y R-I F$ and $C W-I F$ (standard deviations of about $\$ 40$ to $\$ 50 \mathrm{ha}^{-1}$ ), and highest for $C W$ and the uninsured $2 Y R-I F$ and $C W-I F$ rotations (standard deviations of about $\$ 50$ to $\$ 75 \mathrm{ha}^{-1}$ ). In contrast to average annual net returns, which are based on an equal weighting for each year, the most profitable rotations based on the 25-yr discounted NPV were the CW-IF systems with no crop insurance and which used the TSW decision criterion at threshold water levels of $80 \mathrm{~mm}$ or more (Tables 8 and 9). The second highest ranking systems (based on 25-yr total NPV) included these same flex-cropping systems but with participation in the all-risk crop insurance program. Also effective were several of the uninsured $2 Y R-I F$ and $3 Y R-I F$ systems which used the TSW decision criterion set at the higher threshold water levels, and uninsured CW-IF and 3YR-IF systems based on the SSW decision criterion set at the higher threshold water levels. The $\mathrm{F}-\mathrm{W}$ system provided the best performance among the fixed rotations: it was included in a group of rotations that ranked third highest in terms of NPV. The CW system was the least profitable system at this low wheat price, as reported earlier (zentner and Campbell 1988).

At a wheat price of $\$ 147 t^{-1}$, the highest average annual net return and 25-yr NPV were obtained with uninsured CW-IF based on the TSW criteria set at the intermediate water levels of 80 and $95 \mathrm{~mm}$ (mean annual net return of $\$ 54 \mathrm{ha}^{-1}$ and $25-\mathrm{yr}$ NPV of $\$ 739 \mathrm{ha}^{-1}$ ) (Tables 8 and 9). The group of rotations that ranked second highest included the crop insured and uninsured $2 Y R-I F$ systems and other members of the $C W-I F$ system which used the TSW decision criterion (mean annual net return and 25-yr NPV of $\$ 45$ and $\$ 606 \mathrm{ha}^{-1}$, respectively). The $\mathrm{F}-\mathrm{W}, \mathrm{F}-\mathrm{W}-\mathrm{W}$, and several of the $3 Y R-I F$ systems provided similar net returns and generally ranked lower than those of $C W-I F$ and $2 Y R-I F$. The $C W$ system again provided the lowest net returns at this intermediate wheat price. Income variability increased proportionately with the increase in wheat price, but this had little effect on the relative patterns among rotations.

At a wheat price of $\$ 184 \mathrm{t}^{-1}$, the most profitable rotations were generally as discussed for lower prices (Tables 8 and 9). However, there was some tendency for flex-cropping systems at lower threshold water levels to rank higher than those based on higher water levels. This generally supports the findings of Weisensel et al. (1991) who reported that the economic optimum soil water levels at planting time, for wheat and barley, declined with increases in product price. At this high wheat price, the crop insured $F-W-W$ and $C W$ rotations provided higher net returns than the comparable $\mathrm{F}-\mathrm{W}$ rotation; however, if the crops were not insured there was no significant difference among these three fixed rotations. 
Table 8. Net return for fixed and flex-crop rotations, with and without crop insurance, for the available spring soil water decision criterion at three threshold water levels.

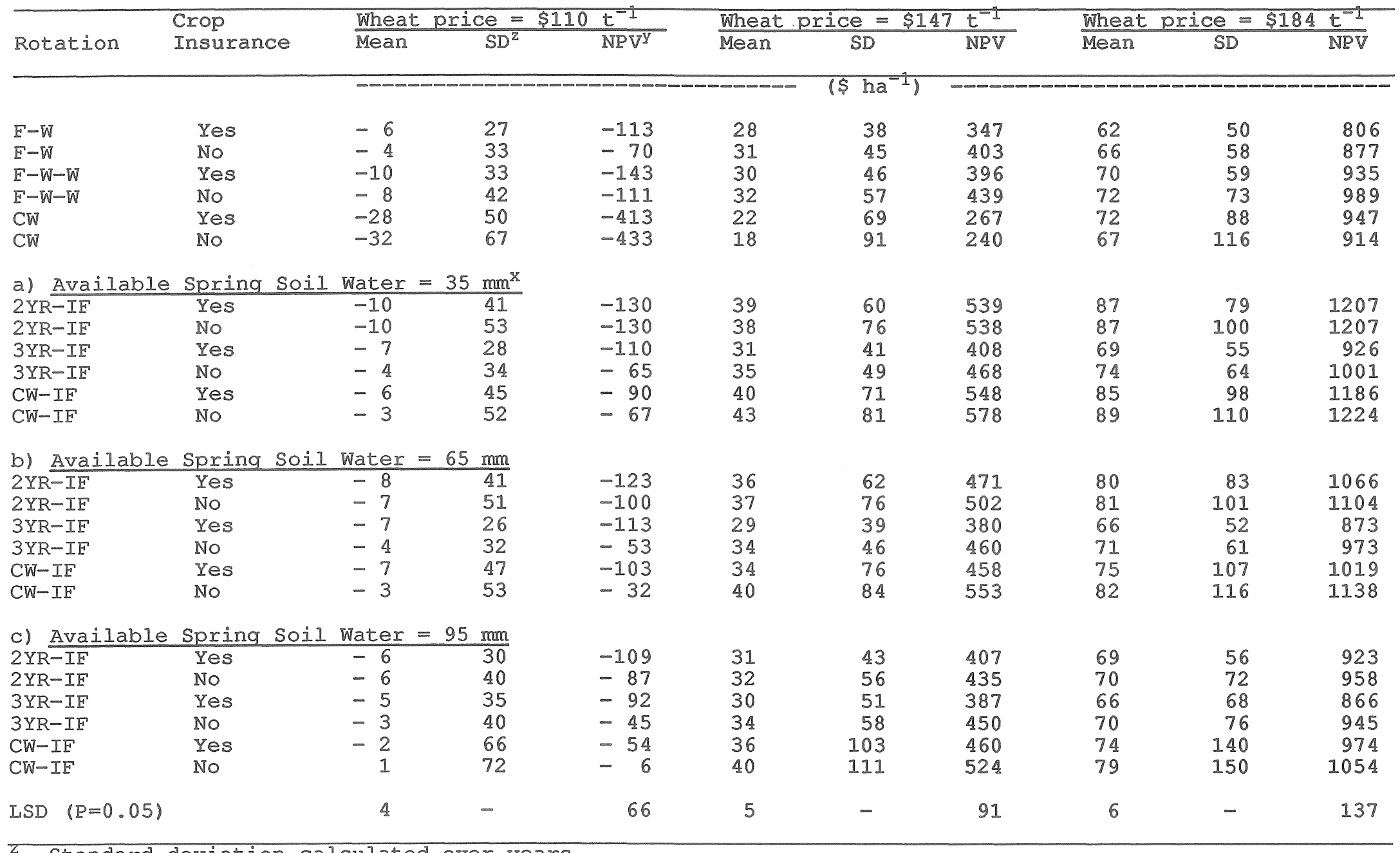

z Standard deviation calculated over years.

$y$ Net present value calculated for the 25 year period using a 5\% discount rate.

x Available spring soil water in the 0- to 120-cm soil depth measured about 1 May. 
Table 9. Net return for flex-crop rotations, with and without crop insurance, for the total available spring water decision criterion at three threshold water levels.

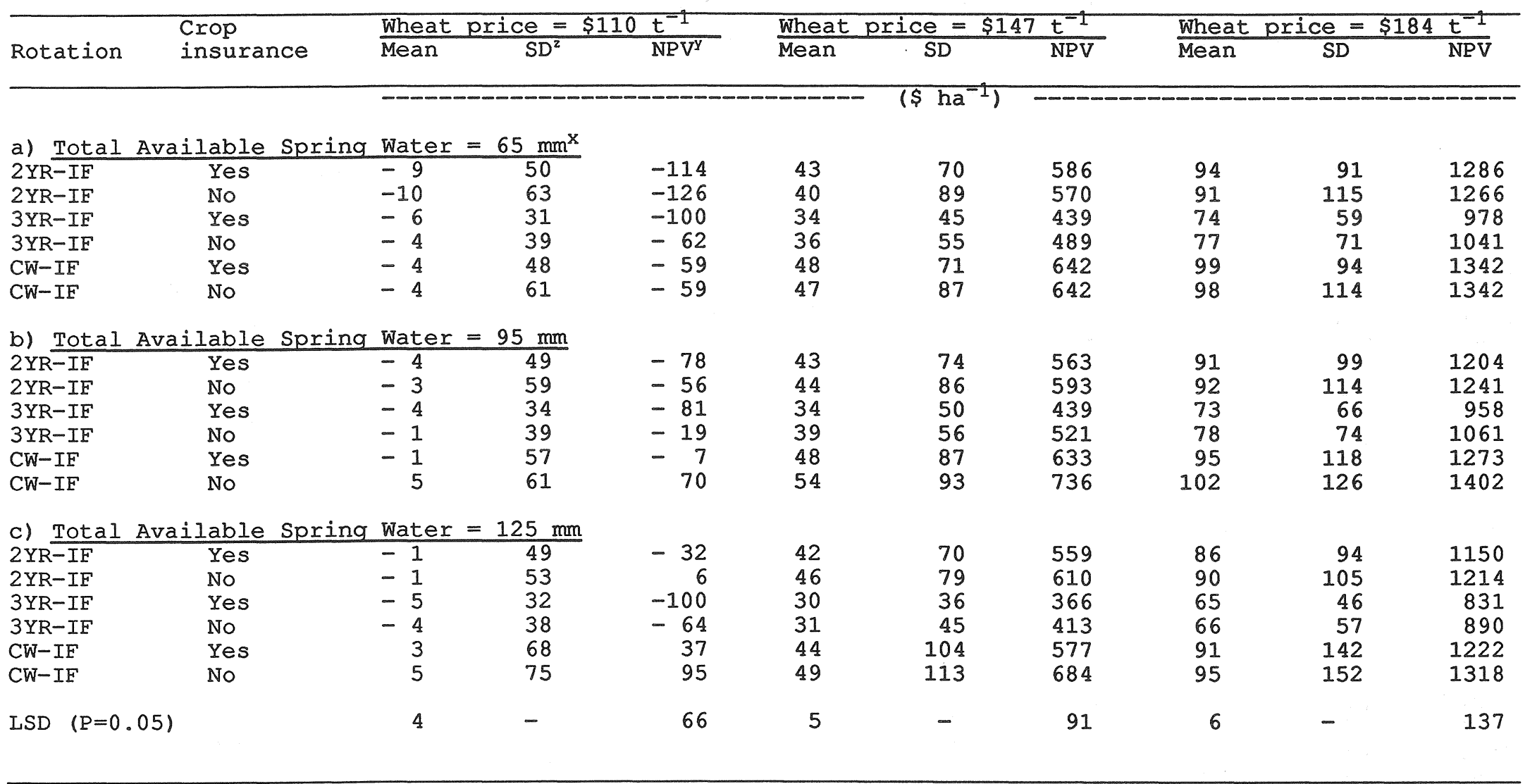

Standard deviation calculated over years.

$y$ Net present value calculated over the 25 year period using a 5\% discount rate.

$x$ Available spring soil water in 0 - to $120-\mathrm{cm}$ soil depth plus precipitation received from date of soil sampling up to 31 May. 
Riskiness of Fixed and Elex-Crop Systems

When the probability distributions of net returns (Fig. 2) were compared for producers possessing different risk preferences, the risk efficient sets contained relatively few rotation systems (Table 10). The flex-cropping systems were generally risk dominant (or risk preferred) to the fixed rotations, except for producers with higher risk aversion (i.e." those who least like to gamble) where $F-W$ and $F-W-W$ were also risk efficient for some wheat price situations. This result is not surprising because fles-cropping systems allow the opportunity to include additional information (i.e., the level of available spring water) in making the crop/fallow decision, compared to that of the fised rotations (Weisensel et al. 1991). The use of TSW was usually superior to SSW as a decision criterion for the flex-cropping policies, due to its higher correlation with final grain yields. As with average annual net returns and NPV, the optimum threshold water levels for the risk efficient flex-cropping systems tended to decline with an increase in wheat price (Tables 8 and 9), coinciding with the choice of more intensive cropping patterns (Table 7).

For producers seeking to masimize expected profit, irrespective of income variability (i.e., risk neutral producers), the best cropping system would be the uninsured CW-IF based on TSW set at $95 \mathrm{~mm}$ when wheat price was $\$ 110$ or $\$ 147 t^{-1}$, and set at $80 \mathrm{~mm}$ when wheat price was $\$ 184 t^{-1}$ (Table 10). These systems correspond to average annual cropping intensities of 3 in 4 years and 4 in 5 years, respectively.

For producers with low risk aversion, the risk efficient set of rotations at low wheat prices included uninsured CW-IF with TSW set at 95 mm and uninsured 3YR-IF with TSW set at 80 or $95 \mathrm{~mm}$ (Table 10). As wheat price increased the risk efficient systems for these producers included rotations with similar or often more intensive cropping patterns than those of risk neutral producers: but for these producers the cropping systems included participation in all-risk crop insurance. The annual cropping intensities for the low risk aversion producers averaged 2 in 3 years, 4 in 5 years, and 9 in 10 years at wheat prices of $\$ 110$, $\$ 147$, and $\$ 184 t^{-1}$, respectively.

As producers become more averse to taking risks, the best cropping systems usually included those that maintained some land in fallow each year (e.g., $3 Y R-I F, F-W$, or $F-W-W)$, safe guarded by the purchase of all-risk crop insurance (Table 10). Further, the acceptable optimum threshold water levels tended to increase with the level of risk aversion. For producers with medium risk aversion the average cropping intensities of the risk efficient systems were 3 in 5 years, 2 in 3 years, and 4 in 5 years at the wheat prices of $\$ 110$, $\$ 147$, and $\$ 184 t^{-1}$, respectively; corresponding values for producers who are highly risk averse ranged between 1 in 2 years and 3 in 5 years. By comparison, Weisensel et a1. (1991) reported a critical spring soil water level of $100 \mathrm{~mm}$ and an average cropping intensity of about 1 in 2 years when wheat price was $\$ 110 t^{-1}$, and $75 \mathrm{~mm}$ of water and a cropping intensity of 7 in 10 years when wheat price was $\$ 147 t^{-1}$

The increasing conservatism in the choice of cropping systems reflects a trade-off that producers face between increases in expected profit and increases in income variability (Zentner and Campbell 1988). Producers with higher risk aversion are usually willing to give up more expected net return in order to "play it safe" compared to those who are less risk averse (Zentner et al. 1992 ). For example, at a wheat price of $\$ 147 \mathrm{t}^{-1}$, the mean and standard deviation of net returns for the risk neutral set of rotations averaged $\$ 54 \mathrm{ha}^{-1}$ and $\$ 93 \mathrm{ha}^{-1}$. respectively: similar values for producers with low risk aversion were $\$ 50$ and $\$ 86 \mathrm{ha}^{-1}$, respectively. These same parameters averaged $\$ 38$ and $\$ 56 \mathrm{ha}$.1 for medium risk averse producers, and $\$ 32$ and $\$ 43 \mathrm{ha}^{-1}$ for producers with high risk aversion. 


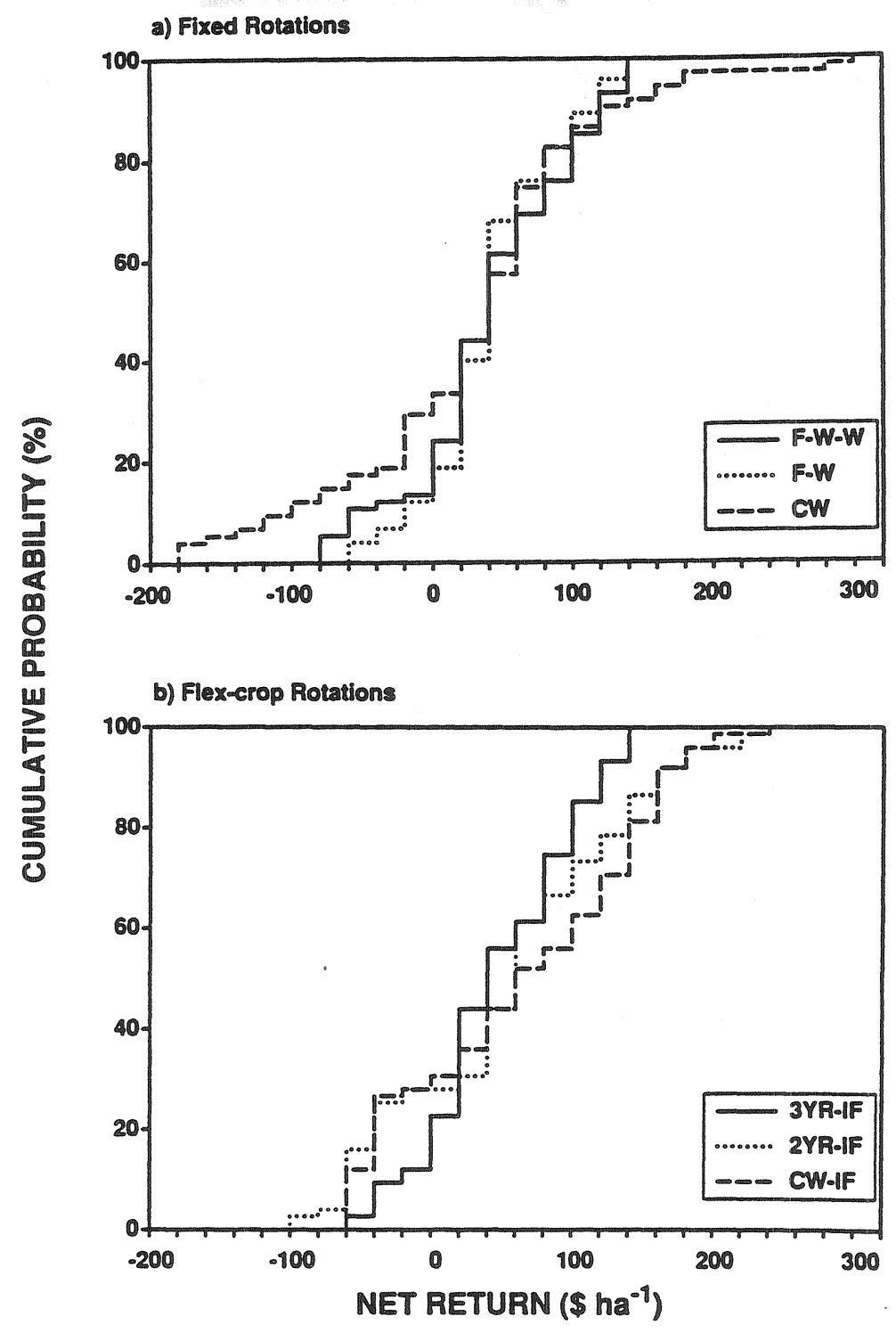

Figure 2. Curnulative probability density functions for fallow-wheat (F-W), fallow-wheat-wheat $(E-W-W)$, continuous wheat (CW), and three flexcropping systems based on the TSW decision criterion set at $80 \mathrm{~mm}$, shown without all-risk crop insurance for a wheat price of $\$ 147 \mathrm{t}^{-1}$. 
Table 10. Sets of risk efficient cropping systems for risk neutral and risk averse producers.

\begin{tabular}{|c|c|c|c|c|}
\hline $\begin{array}{l}\text { Crop } \\
\text { rotation }\end{array}$ & $\begin{array}{l}\text { Decision } \\
\text { criterion }\end{array}$ & $\begin{array}{l}\text { Crop } \\
\text { insurance }\end{array}$ & $\begin{array}{l}\text { Risk } \\
\text { neutral }\end{array}$ & $\frac{\text { Level of risk aversion }}{\text { Low Medium High }}$ \\
\hline
\end{tabular}

a) Wheat Price $=\$ 110 t^{-1}$

$\begin{array}{lll}C W-I F & T S W=95 \mathrm{~mm} & \text { No } \\ 3 Y R-I F & \text { TSW }=80 \mathrm{~mm} & \text { No } \\ 3 Y R-I F & T S W=95 \mathrm{~mm} & \text { No } \\ 3 Y R-I F & S S W=65 \mathrm{~mm} & \text { No } \\ 3 Y R-I F & S S W=80 \mathrm{~mm} & \text { No } \\ F-W & & \text { No } \\ 3 Y R-I F & T S W=110 \mathrm{~mm} & \text { Yes } \\ 3 Y R-I F & S S W=80 \mathrm{~mm} & \text { Yes } \\ T-W & & \text { Yes }\end{array}$

$t^{2}$

+
+
+

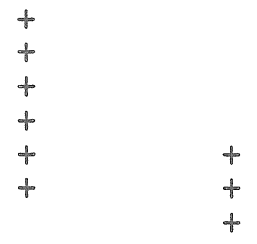

b) Wheat Price $=\$ 147 t^{-1}$

$\begin{array}{llll}C W-I F & \text { TSW }=95 \mathrm{~mm} & \text { No } \\ C W-I F & \text { TSW }=80 \mathrm{~mm} & \text { No } \\ C W-I E & \text { TSW }=65 \mathrm{~mm} & \text { YeS } \\ C W-I F & \text { TSW }=80 \mathrm{~mm} & \text { YeS } \\ 3 Y R-I F & \text { TSW }=80 \mathrm{~mm} & \text { No } \\ 3 Y R-I F & \text { TSW }=95 \mathrm{~mm} & \text { No } \\ 3 Y R-I F & \text { TSW }=65 \mathrm{~mm} & \text { YeS } \\ 3 Y R-I F & \text { TSW }=80 \mathrm{~mm} & \text { YeS } \\ 3 Y R-I F & \text { TSW }=110 \mathrm{~mm} & \text { YeS } \\ E-W & & \text { YeS }\end{array}$

c) Wheat Price $=\$ 184 t^{-1}$ 2YR-IE

CW-IE

2YR-IE

$3 Y R-I E$

$3 Y R-I E$

$F=W-W$

$E-W$
$=80 \mathrm{~mm}$

$T S W=65 \mathrm{~mm}$

$T S W=65 \mathrm{~mm}$

$S S W=35 \mathrm{~mm}$

$\mathrm{TSW}=65 \mathrm{~mm}$

$S S W=50 \mathrm{~mm}$
No

Yes

Yes

Yes

Yes

Yes

Yes

Yes
+
+
+

$+$

+
+
+

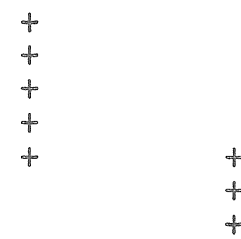

$+$

+
+
+

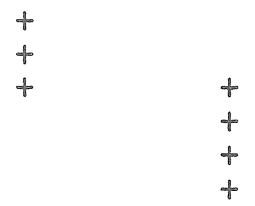

$\mathrm{z}$ t indicates cropping systems which are members of the risk efficient
set for each group of producers. 


\section{CONCLUSIONS}

Results of this 25-yr study showed that for producers located on medium textured soils in southwestern saskatchewan, it is generally more profitable to use available spring water to guide them in their recropping decisions, compared to the traditional procedure of using fixed rotations. By taking into account the level of available spring water at or near the time of planting in their annual crop/fallow decisions, income variability (or risk) can be reduced, particularly when combined with all-risk crop insurance. The benefits of flexcropping systems come from the significant correlation that exists between yields of wheat grown on stubble and the levels of available spring soil water (SSW) and total available spring water (TSW) (SSW plus May precipitation). Consequently. producers can use this information, which can be readily determined prior to planting, as a guide in selecting those years when stubble cropping has a high probability of being profitable. This helps reduce the downside risks associated with conventional stubble cropping practices.

The TSW decision criteria was generally superior to SSW because of its higher correlation with final grain yields (assuming no adverse yield effect from late planting). However, the use of TSW may delay planting on some areas until the end of May (or beyond) which could raise practical problems for producers with regard to organizing the necessary resources and completing field operations in a timely manner. In some years delayed planting may also delay maturity, thereby increasing the risk of reduced yields and grain quality if inclement weather occurs during harvest. Concerns regarding delayed planting apply only to those areas that are subject to the annual crop/fallow decision. Fallow areas and some stubble areas (depending on the flex-cropping system) which are not dependent on the TSW decision criterion can be planted at the usual time, and are thus not prone to these additional concerns.

The best flex-cropping systems varied with expected wheat price and the level of risk aversion held by producers. Higher wheat prices prompted the selection of more intensive cropping systems (CW-IF and $2 Y R-I F$ ) and the use of lower threshold levels of available spring water as guiding criteria, while higher risk aversion favored selection of rotations that maintained some land area in fallow each year (e.g., 3YR-IF), the use of higher threshold water levels, and the inclusion of all-risk crop insurance in the production plan. In all cases the most profitable flex-cropping systems used fallow less frequently than is the tradition with the $F-W$ rotation. The wide-spread adoption of flexcropping by producers could potentially reduce the severity of the soil degradation problems commonly experienced in this region. However, in years when all or a large portion of the farm is fallowed, producers must be careful in choosing the frequency and type of tillage implements used for weed control so as to minimize the potential of soil erosion. Area producers wanting to implement flexible cropping systems must also be cognizant of recent changes in government policies and programs (e.g., Gross Revenue Insurance Plan), some of which could impact negatively, or positively, on the merits of these production options.

\section{ACKNOWLEDGEMENT}

Funding for this study was provided by a grant to RM \#259 Eston Crop Club under the Canada-Saskatchewan Agreement for Environmental Sustainability.

\section{REFERENCES}

Anderson, C.H., and Hennig, A.M.F. 1963. The effect of date of seeding and fertility level on the yield of wheat, oats, and barley in northwestern Alberta. Can. J. Plant Sci. 44:15-20.

Campbell, C.A., Zentner, R.P., Dormaar, J.F., and Voroney, R.P. 1986. Land quality, trends and wheat production in western Canada. p. 318-353. A.E. Slinkard and D.B. Fowler, (eds.). Wheat Production in Canada - A review. University of Saskatchewan, Saskatoon, Sask.

Doll, J.P., and Orazem, F. 1978. Production economcis: Theory with applications. Grid Inc., Columbus, Ohio. 406 pp. 
Janzen, P.J., Rorven, N.A., Harris, G.K., and Lehane, J.J. 1960. Influence of depth of moist soil at seeding time and seasonal rainfall on wheat yields in southwestern Saskatchewan. Publ. 1090. Canada Department of Agriculture, ottawa, ont. $10 \mathrm{pp}$.

Iittle, T.M., and Hills, E.T. 1978. Agricultural experimentation - Design and analysis. John Wiley and Sons, New York. 350 pp.

Saskatchewan Agriculture and Food. 1991. Farm machinery custom and rental rate guide 1991. Publ. 6M, Saskatchewan Agriculture and Food, Regina, Sask. 33 pp.

Staple, W.J. and Lehane, J.J. 1954. Wheat yield and use of moisture on substations in southern Saskatchewan. Can. J.Agric. Sci. 34:460-468.

Weisensel, W.P. Van Kooten, G.C., and Schoney, R.A. 1991. Relative riskiness of fised vs. flexible crop rotations in the dryland cropping region of western Canada. Agribusiness 7:551-560.

zentrer, R.P., and Campbell, C.A. 1988. First 18 years of a long-term crop rotation study in southwestern Saskatchewan - yields, grain protein, and economic performance. Can. J. Plant Sci. 68:1-22.

zentner, R.P., Selles, F., Campbell, C.A., Handford, $K$, and McConkey, B.G. 1992. Economics of nitrogen fertilizer management for zero till continuous spring wheat in the Brown Soil zone. Can. J. Plant sci. (In Press). 